\title{
Pelatihan TOEP Bagi Mahasiswa
}

\author{
Rizky Lutviana $^{1}$, Siti Mafulah ${ }^{2}$ \\ ${ }^{1,2}$ Universitas Kanjuruhan Malang \\ 1e-mail: lutviana.rizky@unikama.ac.id \\ ${ }^{2}$ e-mail: ulfasengkaling@gmail.com
}

\begin{abstract}
Abstrak
Kemampuan berbahasa Inggris yang dibuktikan dengan sertifikat keahliah berbahasa Inggris seperti TOEP merupakan salah satu pesyaratan yang umum digunakan dalam rangka melamar pekerjaan ataupun melanjutkan studi ke jenjang yang lebih tinggi. Oleh karena itu, mahasiswa perlu diberikan bekal kemampuan berbahasa Inggris yang dibuktikan dengan sertifikat. Permasalahan yang dihadapi oleh mitra program pengabdian masyarkat ini adalah (1) Kurang tersedianya materi ajar yang up to date and lengkap, (2) materi kurang terkoordinir dengan baik, (3) tersedianya waktu yang singkat untuk pelatihan, dan (4) nilai rata-rata yang rendah. Solusi dari permasalahan tersebut adalah memberikan pelatihan TOEP secara rutin selama 2 minggu, 4 pertemuan setiap kelas yang berisikan (1) pemberian materi mengenai pentingya kemampuan bahasa Inggris dalam era saat ini, (2) pelatihan TOEP dengan menggunakan metode pengajaran note taking untuk Listening Section (3) pelatihan TOEP dengan menggunakan metode error analysis untuk Structure and Written Expression Section, dan (3) pelatihan TOEP dengan menggunakan metode metacognitive strategy untuk Reading Section. Hasil yang didapat dari pelatihan ini adalah peningkatan skor TOEP mahasiswa.
\end{abstract}

Kata Kunci : kemampuan Bahasa Inggris, pelatihan,TOEP

\section{PENDAHULUAN}

Unviversitas Kanjuruhan Malang merupakan salah satu Universitas swasta di Malang yang memiliki 6 fakultas, 17 program studi, dan sekitar 9000 mahasiswa. Kemampuan berbahasa Inggris merupakan salah satu kemampuan yang wajib dimiliki oleh lulusan Universitas Kanjuruhan Malang. Hal ini nampak pada dijadikanya Bahasa Inggris menjadi matakuliah umum wajib pada semua program studi. Selain itu, sebelum lulus, mahasiswa diwajibkan untuk menempuh tes TOEP sebagai bekal menghadapi dunia kerja yang sudah umum telah menjadikan kemapuan Bahasa Inggris yang dibuktikan dengan sertifikat sebagai salah satu persyaratan dalam melamar pekerjaan dan/atau melanjutkan studi ke jenjang yang lebih tinggi. Penyelenggaraan TOEP dikoordinir oleh lembaga bahasa Universias Kanjuruhan Malang yang bernama LAC (Language Access Center). LAC mengadakan pelatihan TOEP dua kali dalam 1 tahun, yaitu pada bulan Agustus dan Maret. Pelatihan tersebut berlangsung selama 2 minggu, materi yang diajarkan terdiri dari 2 sesi. Sesi pertama adalah merujuk pada pentingnya pelatih tersebut LAC membutuhkan instruksi yang handal. 


\section{SUMBER INSPIRASI}

Mitra dalam pelatihan ini adalah lembaga bahasa LAC dan 6 Fakultas di Universitas Kanjuruhan Malang. Permasalahan yang dihadapi oleh mitra-mitra tersebut adalah: (1) Kurang tersedianya materi ajar yang up to date and lengkap. Sumber materi ajar yang terdapat pada LAC adalah buku referensi terbitan tahun 1990. Selain itu, (2) materi kurang terkoordinir dengan baik. Materi yang diajarkan sedikit berbeda dangan materi yang ada pada tes, dan juga topik pembahasan materi yang tidak merata, misalnya untuk reading section, sebagaian besar topik berkaitan dengan ilmu pengetahuan alam, dan kurang mengenai ilmu bidang lain, seperti ilmu sosial, sejarah, atau bahasa, sehingga mahasiswa memiliki kosa-kata yang terbatas. Kemudian, (3) tersedianya waktu yang singkat untuk pelatihan, yaitu selama 2 minggu, 4 pertemuan setiap kelas. Waktu yang singkat tersebut membutuhkan suatu strategi khusus dalam pengajaran dan pengerjaan soal. Yang terakhir (4)nilai rata-rata yang rendah.

Dari permasalahan tersebut yang telah diuraikan pada bagian sebelumnya, solusi yang ditawarkan adalah: (1) pemberian materi mengenai pentingya kemampuan bahasa Inggris dan pentingnya mendapatkan kualifkasi kemampuan bahasa Inggris yang dibuktikan dengan sertifikat skor TOEP, (2) pelatihan TOEP dengan menggunakan metode pengajaran note taking untuk Listening Section (3) pelatihan TOEP dengan menggunakan metode error analysis untuk Structure and Written Expression Section, dan (3) pelatihan TOEP dengan menggunakan metode metacognitive strategy untuk Reading Section.

Dalam melaksanakan pelatihan tersebut, prosedur/langkah-langkah yang dilaksanakan adalah (1) memberikan kuliah umum tentang pentingnya pelatihan TOEP kepada sekitar 200 mahasiswa dari Fakultas Sain dan Teknologi (terdiri dari 4 Program Studi), yang berlangsung selama selama 6 jam, (2) memberikan pre-test kepada mahasiswa pada awal pertemuan pelatihan, (3) memberikan pelatihan TOEP yang berjalan selama 6 pertemuan (berlangsung selama 2 minggu, yang terdiri dari: (1) pertemua pertama, pretest, (2) pertemuan kedua penyampaian materi strategi dalam menjawab pertanyaan pada Listening Section, (3) pertemuan ketiga penyampaian materi strategi dalam menjawab pertanyaan pada Structure and Written Expression Section, (4) pertemuan keempat penyampaian materi strategi dalam menjawab pertanyaan pada Listening Section, (5) pertemuan kelima penyampaian materi strategi dalam menjawab pertanyaan pada Reading Section, dan (6) pertemuan keenam adalah pelaksanaan post test. Setelah post test, skor akan dihitung dan kemudian akan dilakukan evaluasi terhadap kegiatan dengan menyebarkan angket.

Partisipasi mitra, khususnya pihak fakultas dan LAC, dalam kegiatan tersebut adalah menyediakan sarana dan prasarana dalam pelaksanaan pelatihan TOEP tersebut. Sarana dan prasarana tersebut adalah penyediaan gedung untuk kuliah umum, penyediaan lab bahasa, dan penyediaan ATK. Sedangkan mitra lainya, yaitu mahasiswa partisipasinya adalah sebagai peserta kegiatan pelatihan dan berpartisipasi dalam memberikan masukan akan program yang telah berjalan melalui pengisian angket.

\section{III.METODE KEGIATAN}

Pelatihan TOEP dilaksanakan pada 14 Agustus sampai dengan 18 September 2017. Peserta adalah mahasiswa Universitas Kanjuruhan Malang semester 8, Fakultas Sanis 
dan Teknologi, yang terdiri dari 4 program studi, yaitu Prodi Matematika 81 mahasiswa, Prodi Fisika 50 mahasiswa, Prodi Teknik Informatika 144 mahasiswa, dan Sistem Informatika 70 mahasiswa, jadi total mahasiswa berjumlah 345 orang. Mahasiswa berasal dari berbagai latar belakang dan mempunyai kemampuan berbahasa Inggris yang beragam. Mahasiswa pada semua program studi telah menempuh matakuliah bahasa Inggris dasar dan Bahasa Inggris profesi. Meskipun demikian, mahasiswa masih asing dengan tes TOEP. Pada saat pre-test, sekitar $80 \%$ mahasiswa tidak dapat menyelesaikan semua soal sesuai dengan waktu yang ditentukan. Mahasiswa mengerjakan soal tidak menggunakan strategi yang efektif, sehingga nilai pretest rata-rata mahasiswa adalah 370, skor yang tergolong rendah.

Metode dalam pelaksanaan kegiatan pelatihan TOEP adalah: (1) kuliah umum tentang pentingnya kemampuan dan keterampilan berbahasa Inggris, (2) memberikan materi tentang bentuk dan struktur tes TOEP dalam pembelajaran di kelas, dan (3) memberikan strategi khusus dalam mengerjakan soal listening, reading, dan structure and written expression.

\section{ULASAN KARYA BERUPA JASA}

Dampak nyata dari hasil kegiatan pelatihan TOEP ini adalah (1) tersedianya modul pelatihan dengan materi yang terkini dan terorganisir, (2) mahasiswa mendapatkan ilmu dan strategi dalam mengerjakan tes TOEP, dibuktikan dari hasil kuesioner, (3) mahasiswa mendapatkan hasil tes TOEP yang memuaskan, dibuktikan dari hasil nilai rata-rata.

Modul pelatihan TOEP disusun oleh pengabdi yang berisikan rangkuman materi, contoh soal dan pembahasan, serta kompilasi soal latihan menjelang tes yang diadaptasi dari soal tes TOEP karya Deborah Phillips (Phillips, 2001). Modul pelatihan ini dibagikan kepada seluruh peserta sebagai buku pegangan. Selain itu, didalam modul juga terdapat trik dan tips singkat dalam mengerjakan tes TOEP(Gambar 1).

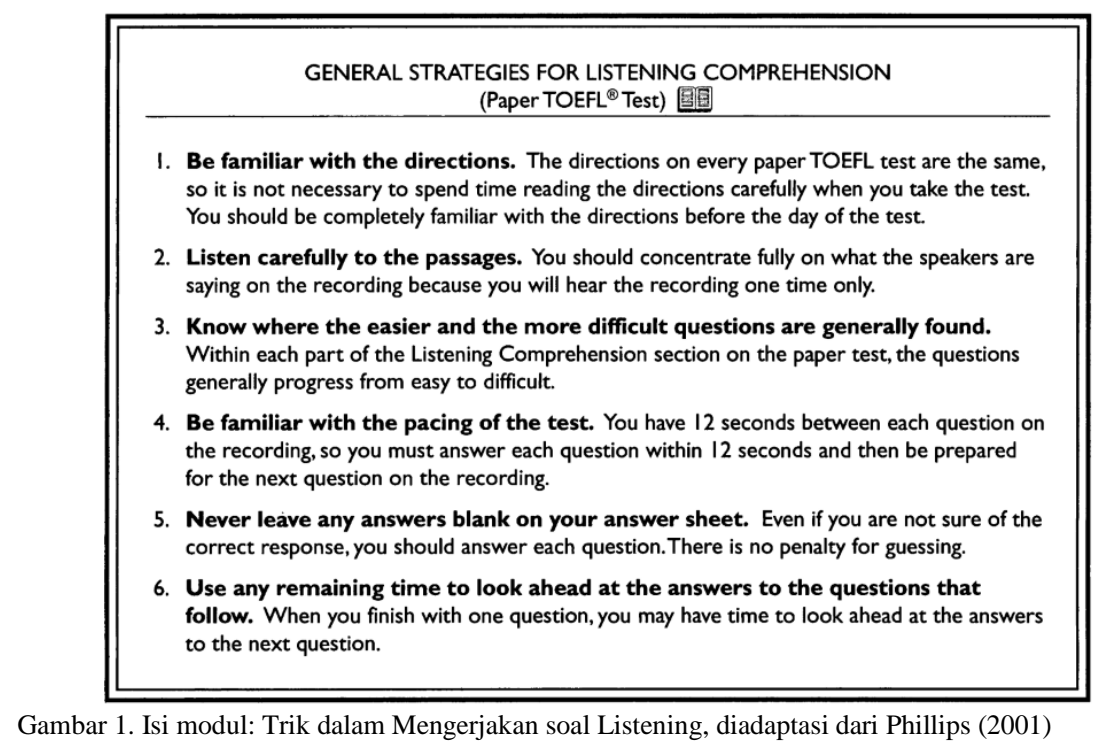

Pemberian materi yang diajarkan listening section menggunakan metode note dikelas menggunakan 3 strategi, yaitu untuk taking, untuk reading section menggunakan 
metacognitive strategy, dan structure and written expression section menggunakan error analysis. Metode note taking adalah metode dimana mahasiswa mengidentifikasi jenis dan isi dari ujaran yang disampaikan dalam pembicaraan baik dialog maupun monolog. Metode ini membantu mahasiswa untuk lebih focus dan berfikir secara terorganisir saat mendengarkan ujaran bebahasa Inggris. Dalam note taking, mahasiswa diarahkan agar dapat menangkap inti/ide pokok dari ujaran dan informasi detail yang yang terkandung dalam ujaran dengan mengidentifikasikan 5 hal pertanyaan mendasar: what (apa), where (dimana), when (kapan), why (mengapa), dan how (bagaimana).

Selanjutnya, untuk reading section, mahasiswa diajarkan menggunakan metode metacognitive strategy oleh Nejad \&Shahrebabaki (2015) yang disebut
Comprehension of English Language Learners Through Cognitive Academic Language Learning Approach (CALLA). CALLA terdiri dari 5 tahap, yaitu: (1) tahap yang disebut persiapan dimana mahasiswa mengidentifikasikan strategi dalam reading section yang telah mereka gunakan efektif atau tidak, (2) Presentasi, yaitu pengajar memberikan model/mendemonstradikan contoh dalam mengintepretasikan makna bacaan melalui petunjuk kosa-kata, mengidentifikasikan ide pokok, serta skaning teks untuk memahami teks secara detail. (3) mahasiswa mempraktekkan strategi nomor 2 untuk menjawab teks, (4) siswa melakukan evaluasi terhadap strategi yang mereka gunakan, dan (5) menerapkan strategi yang dirasa mudah bagi siswa untuk mengerjakan soal reading section. Langkah-langkah dari strategi ditunjukkan dalam Gambar 2.

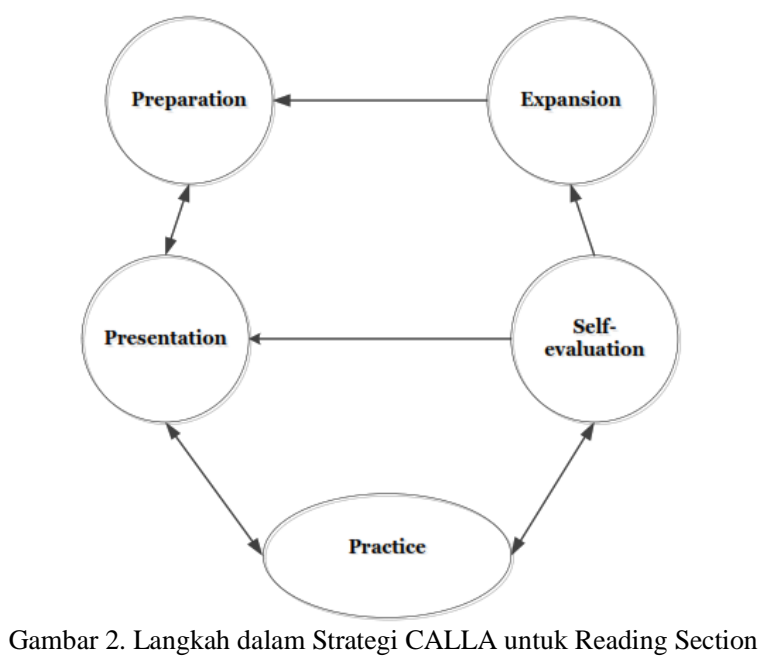

Setelah reading section, pemateri memberikan strategi dalam mengerjakan soal structure and written expression. Strateg yang digunakan adalah error analysis. Error analysis merupakan strategi dimana mengidentifikasi kesalahan tata Bahasa dalam sebuah ujaran tulis. Sebelum siswa dapat menderapkan strategi ini, mereka harus mendapatkan materi mengenai tata Bahasa Inggris (English Grammar). Dalam hal ini pemayeri telah membuat ringkasan materi yang mudah dipahami dan dihafalkan. Metode ini membuat siswa lebih kritis dan lebh memahami materi sehingga dalam mengerjakan soal tidak akan mendapatkan kesulitan, karena soal yang diujikan juga sebagaian besar berupa analisis tata bahasa. 


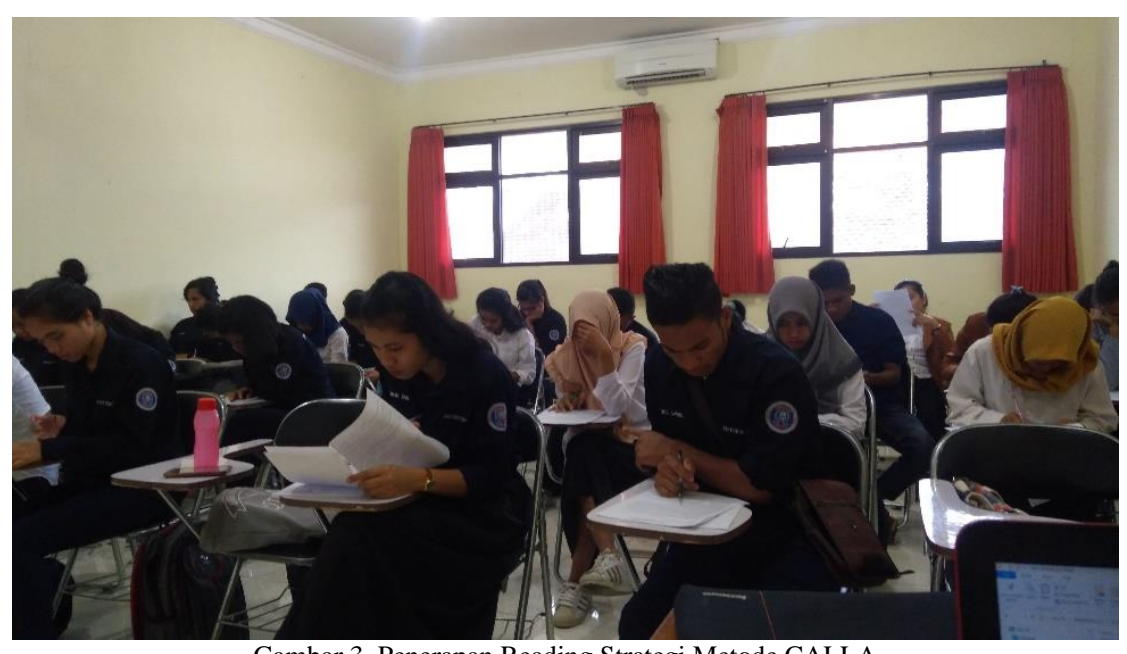

Gambar 3. Penerapan Reading Strategi Metode CALLA

TOEFL EXERCISE (Skills 49-51): Choose the letter of the underlined word or group of words that is not correct.

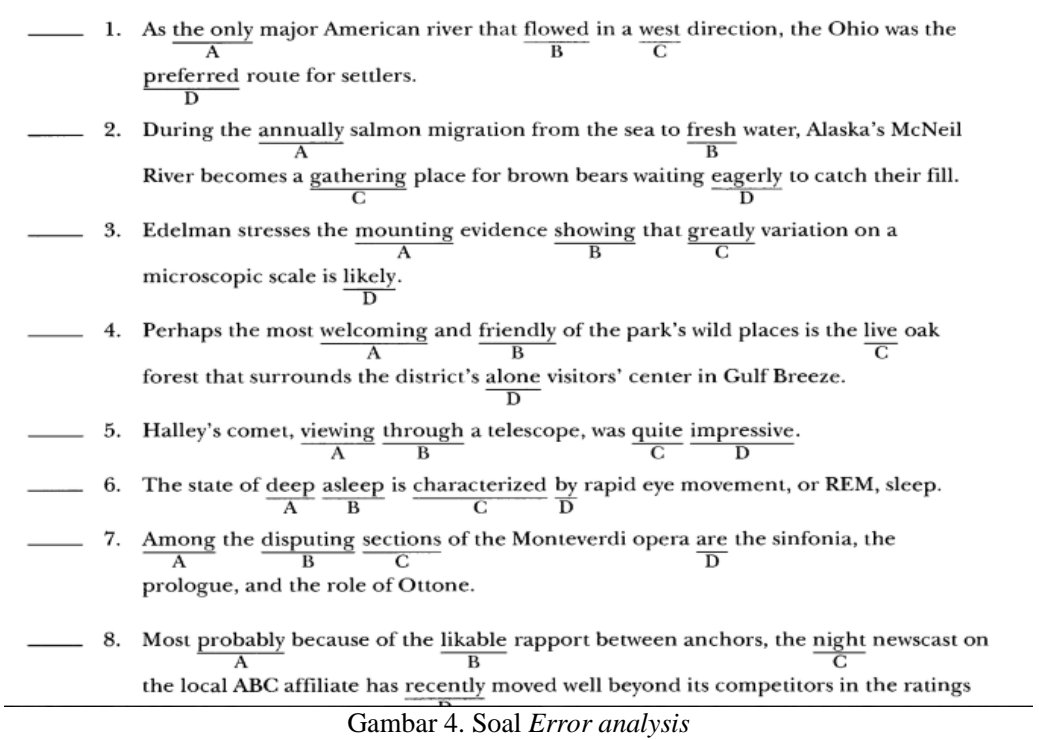

Setelah diberikan materi selama 6 pertemuan, peserta pelatihan melaksanakan tes TOEP selama 2 jam 30 menit yang dibagi menjadi 3 sesi, listening section 60 menit (50 soal), reading section 60 menit (50 soal), dan structure and written expression section 30 menit (40 soal). Setelah tes dilakukan penghitungan skor setiap siswa. Metode penskoran berbasarkan konfersi nilai oleh Phillips (2001). Hasil skor pre tes dan post tes siswa ditunjukkan dalam Tabel 1.

Jika dibandingkan dengan skor pre test, nilai post test mahasiswa mengalami kenaikan.
Hal ini juga ditunjukkan dengan nilai rata-rata. Nilai rata-rata pre test 400 dan nilai rata-rata post test 510. Kenaikan yang signifikan ini ditunjukkan dengan semangat dan respon siswa yang juga positif terhadap pelatihan ini.

Untuk mengetahui respon siswa dan tingkat kepuasan siswa terhadap pelatihan ini, dilakukan pengisian angket mengenai pelatihan TOEP setelah tes dilaksanakan. Semua siswa berpartisipasi dalam pengisian angket. Pengisian angket dibimbing dan diawasi langsung oleh pemateri sehingga didapatkan hasil yang cukup akurat. Hasil 
angket dirangkum dan ditunjukkan dalam Tabel 2.

Tabel 2 menunjukkan respon mahasiswa terhadap pelatihan TOEP yang telah berlangsung. Pada pernyataan $189.2 \%$ mahasiswa setuju bahwa mereka mendapatkan bekal yang cukup selama pelatihan, 92.6\% mahasiswa setuju bahwa materi yang disampaikan memberikan pengetahuan yang cukup dalam mengerjakan tes TOEP (pernyataan 2), $95.8 \%$ mahasiswa setuju bahwa materi mengenai trik dalam pengerjaan soal membantu mereka dalam mengerjakan tes (pernyataan 3), 94.2\% mahasiswa setuju bahwa Pengajar cukup ramah dan berkompeten dalam memberikan pelatihan
TOEP, dan75\% mahsiswa setuju bahwa Fasilitas yang tersedia untuk pelatihan baik dan cukup memadai

Tabel 1. Skor Pretest dan Post Test

\begin{tabular}{lcc}
\hline \multirow{2}{*}{$\begin{array}{c}\text { Rentang Nilai } \\
\text { Skor }\end{array}$} & \multicolumn{2}{c}{ Jumlah Mahasiswa } \\
\cline { 2 - 3 } & $\begin{array}{c}\text { Pre test } \\
\text { (orang) }\end{array}$ & $\begin{array}{c}\text { Post test } \\
\text { (orang) }\end{array}$ \\
\hline$<=400$ & 75 & 0 \\
$401-450$ & 186 & 53 \\
$451-500$ & 40 & 147 \\
$501-550$ & 44 & 118 \\
$551-600$ & 0 & 24 \\
$651-700$ & 0 & 3 \\
\hline Total & 345 & 345 \\
\hline Nilai Rata-rata & 400 & 510 \\
\hline
\end{tabular}

Tabel 2. Hasil Kuesioner tentang Pelatihan TOEP

\begin{tabular}{|c|c|c|c|c|c|}
\hline \multirow[t]{2}{*}{ Pernyataan } & \multicolumn{5}{|c|}{ Respon (jumlah mahasiswa) } \\
\hline & $\begin{array}{l}\text { Sangat } \\
\text { setuju }\end{array}$ & Setuju & $\begin{array}{c}\text { Ragu- } \\
\text { ragu }\end{array}$ & $\begin{array}{l}\text { Tidak } \\
\text { setuju }\end{array}$ & $\begin{array}{l}\text { Sangat } \\
\text { tidak } \\
\text { setuju }\end{array}$ \\
\hline $\begin{array}{l}\text { Saya mendapatkan bekal } \\
\text { pelatihan yang cukup dalam } \\
\text { pelatihan TOEP ini }\end{array}$ & $\begin{array}{c}16.5 \% \\
(57)\end{array}$ & $\begin{array}{l}72.7 \% \\
(251)\end{array}$ & $\begin{array}{c}8.7 \% \\
(30)\end{array}$ & $\begin{array}{c}0.5 \% \\
(2)\end{array}$ & $\begin{array}{l}2 \% \\
(7)\end{array}$ \\
\hline $\begin{array}{l}\text { Materi yang disampaikan } \\
\text { memberikan saya pengetahuan } \\
\text { yang cukup dalam mengerjakan } \\
\text { tes TOEP }\end{array}$ & $\begin{array}{c}30 \% \\
(103)\end{array}$ & $\begin{array}{c}62.6 \% \\
(216)\end{array}$ & $\begin{array}{c}6.6 \% \\
(23)\end{array}$ & $\begin{array}{c}0.8 \% \\
(3)\end{array}$ & $0 \%$ \\
\hline $\begin{array}{l}\text { Trik dalam pengerjaan soal } \\
\text { banyak membantu saya dalam } \\
\text { mengerjakan tes TOEP }\end{array}$ & $\begin{array}{c}35 \% \\
(121)\end{array}$ & $\begin{array}{c}60.8 \% \\
(210)\end{array}$ & $\begin{array}{c}3.5 \% \\
(12)\end{array}$ & $\begin{array}{c}0.05 \% \\
\text { (2) }\end{array}$ & $0 \%$ \\
\hline $\begin{array}{l}\text { Pengajar cukup ramah dan } \\
\text { berkompeten dalam } \\
\text { memberikan pelatihan TOEP }\end{array}$ & $\begin{array}{c}25.5 \% \\
(88)\end{array}$ & $\begin{array}{c}68.7 \% \\
(237)\end{array}$ & $\begin{array}{l}4 \% \\
(14)\end{array}$ & $\begin{array}{c}1.7 \% \\
(6)\end{array}$ & $0 \%$ \\
\hline $\begin{array}{l}\text { Fasilitas yang tersedia untuk } \\
\text { pelatihan baik dan cukup } \\
\text { memadai }\end{array}$ & $\begin{array}{c}21.4 \% \\
(74)\end{array}$ & $\begin{array}{c}53.6 \% \\
(185)\end{array}$ & $\begin{array}{c}13.9 \% \\
(48)\end{array}$ & $\begin{array}{l}8.7 \% \\
(30)\end{array}$ & $\begin{array}{c}2.3 \% \\
(8)\end{array}$ \\
\hline
\end{tabular}

\section{KESIMPULAN DAN SARAN}

Dari uraian diatas, dapat disimpulkan bahwa pelatihan TOEP bagi mahasiswa dapat membantu siswa untuk mendapatkan bekal ilmu dan keterampilan berbahasa Inggris untuk menunjang karir atau studi mereka jika ingin meneruskan studi ke jenjang yang lebih tinggi.
Metode pengajaran selama pelatihan yaitu listening section menggunakan metode note taking, untuk reading section menggunakan metacognitive strategy, dan structure and written expression section menggunakan error analysis dapat digunakan untuk mengajarkan 
materi TOEP kepada mahasiswa diluar jurusan Bahasa Inggris.

Agar program pelatihan dapat berjalan dengan baik, perlu diperhatikan beberapa masukan dari mahasiswa, yaitu dukungan fasilitas. Diperlukan laboratorium yang baik untuk mengajarkan materi listening, tidak hanya speaker, melainkan juga dilengkapi fasilitas computer dan LCD. Selain itu, merujuk pada manfaat pelatihan ini, diperlukan waktu yang lebih banyak dan intensif dalam pelatihan kedepannya.

\section{DAFTAR PUSTAKA}

Nejad, B. S.\&Shahrebabaki, M. M. Effects Of Metacognitive Strategy Instruction On The Reading Comprehension Of English Language Learners Through Cognitive Academic Language Learning Approach (CALLA). International Journal of Languages Education and Teaching.3(2).(2015). 133-164.

Sharpe, P.J.Barron's TOEFL iBT: InternetBased Test, $12^{\text {th }}$ Editions. Jakarta: Binarupa Aksara,2007 